\title{
Uma narrativa sobre os cursos superiores em Administração da FACE/UFMG: dos primeiros anos à sua unificação em 1968
}

\author{
A narrative on the higher education courses in Administration of FACE/UFMG: from the \\ early years until their unification in 1968
}

Amon Barros ${ }^{1}$

\section{Resumo}

Apresentamos o desenvolvimento dos cursos superiores em Administração da Faculdade de Ciências Econômicas da Universidade Federal de Minas Geraus (Face/UFMG) entre sua fundação e 1968, quando se deu a fusão dos três cursos existentes. $O$ estudo se justifica pelo importante papel que as graduações em Administração têm e tiveram para disseminar o management. Lançamos luz sobre a história dos cursos de Administração da FACE/UFMG, destacando o estabelecimento de seus cursos de Administração Pública e Sociologia e Política, em 1952, e de Administração de Empresas, em 1954. Destacamos, ainda, a saída da FACE/UFMG do acordo de 1959, envolvendo outros cursos superiores que existiam ou estavam para ser criados no país. Sequencialmente, apresentamos um panorama de trajetória dos cursos superiores em Administração da FACE/UFMG na década de 1960, que culminou em sua unificação em 1968. Concluímos afirmando a importância de resgatar a história dos cursos de graduação como uma das maneiras para compreender o cenário atual da área, bem a necessidade de considerar o desenvolvimento da Administração no Brasil um processo não natural e repleto de complexidades, que deve ser analisado de uma perspectiva aberta à interação entre fatores internos e externos.

Palavras-chave: Americanização. História da Administração. História dos cursos de Administração brasileiros.

\begin{abstract}
We present the development of the higher education courses in Administration of FACE/UFMG between its creation and 1968, when the merger of its three courses took place. The study is justified by the important role that the undergraduate courses in Administration play and played to spread management. We shed some light on the history of the courses in Administration of FACE/UFMG, highlighting the establishment of its courses in Public Administration and Sociology and Politics, in 1952, and in Business Administration, in 1954. We also emphasize that FACE/UFMG was not included in the agreement signed in 1959, involving other existing higher education courses or some courses that were about to be created in the country. Sequentially, we present an overview of the route of the higher education courses in Administration of FACE/UFMG in the 1960 s, culminating in their unification in 1968 . We conclude by claiming the importance to recall the history of the undergraduate courses as a way to understand the current scenario in the area, as well as the need to regard the development of Administration in Brazil as a not natural process that is full of complexities and must be analyzed from a perspective open to interaction between domestic and foreign factors.
\end{abstract}

Keywords: Americanization. History of Administration. History of the Brazilian courses in Administration.

Artigo submetido em 23 de junho de 2013 e aceito para publicação em 29 de janeiro de 2014

1 Doutor em administração pela Universidade Federal de Minas Gerais - CEPEAD; Professor assistente da FGV-EAESP. Endereço: FGV-EAESP - Escola de Administração de Empresas de São Paulo. Rua Itapeva, 474, 11ํandar - sala 1103 - Bela Vista, CEP $01332-$ 000, São Paulo - SP, Brasil. Email: amon.barros@fgv.br 


\section{Considerações Iniciais}

Este trabalho tem como objetivo apresentar o desenvolvimento dos cursos de Administração da Faculdade de Ciências Econômicas (FACE) da Universidade Federal de Minas Gerais (UFMG), desde sua criação em 1952, até sua unificação em 1968. Ao fazê-lo, buscamos salientar como uma iniciativa aparentemente distante do centro de produção do conhecimento em Administração, os Estados Unidos, estabeleceu-se tendo o modelo de ensino estadunidense como referência. Isso também se deve à importância das escolas de Administração na disseminação de certo modelo de Administração à "americana", que sustenta o que vem sendo chamado de management como conceito que transcende as técnicas de gestão e abrange também um conjunto de valores disseminado por diversas esferas sociais (PARKER, 2002; WOOD JR., TONELLI e COOKE, 2011).

Para Miclethwait e Wooldridge (2003) há quatro veículos principais de disseminação do management: as empresas multinacionais, as consultorias, os pensadores do management (gurus) e as escolas de Administração (business schools) - estas últimas as responsáveis pelo que os autores chamam de management industry. As escolas de Administração assumiram no Brasil características peculiares. Tal fato se deve aos elementos específicos do contexto local, e é observado também em outros países (LOCKE, 1996), ainda que a orientação hegemônica seja sempre inspirada em modelos de origem estadunidense.

Nesse sentido, a FACE estabeleceu uma organização com características singulares, especialmente nos seus primeiros anos, ainda que tenha contado com o apoio de um consultor estadunidense. O desenvolvimento de características únicas também é percebido em outras escolas, como a Faculdade de Economia, Administração e Contabilidade da Universidade de São Paulo (MARTINS, 1989; VALE, 2012) e a Escola de Administração de Empresas de São Paulo (EAESP), ligada à Fundação Getulio Vargas (FGV) (ALCADIPANI e BERTERO, 2012a; 2012b).

Assim, como se nota, os cursos de graduação em Administração brasileiros vêm sendo alvo de reflexões, especialmente em relação ao contexto no qual se estabeleceram, bem como à sua adequação ou não ao contexto do país (MOTTA, 1983; MARTINS, 1989; NICOLINI 2003; COELHO, 2006; SPIANDORELLO, 2008;ALCADIPANI e BERTERO 2012b; VALE, 2012; BARROS e CARRIERI, 2013). Na mesma linha e visando resgatar a história a fim de melhor compreender o presente da área e o desenvolvimento do campo no país, objetivamos discutir o estabelecimento dos cursos de administração ministrados na FACE - que estão entre os primeiros a serem instituídos no Brasil - em conjunto com aqueles oferecidos pela FGV. Ao fazê-lo, apontamos como uma iniciativa com aspectos idiossincráticos terminou por convergir com os padrões de ensino disseminados pelos Estados Unidos e pela EAESP.

Os cursos de Administração Pública e Sociologia e Política da Faculdade, que eram geminados, foram criados em 1952, alguns meses depois do curso da Escola Brasileira de Administração Pública (EBAP), atual Escola Brasileira de Administração Pública e de Empresas (EBAPE). O curso de Administração de Empresas da FACE, por sua vez, foi estabelecido em 1954, sua primeira turma iniciou as aulas em 1955. Estes cursos foram, assim, pioneiros no ensino superior em Administração no Brasil, ainda que sejam pouco mencionados na literatura que trata da história da disciplina no país. O presente artigo, no qual visamos, também, contribuir para o resgate do lugar desses cursos, é parte de uma pesquisa mais extensa que buscava, basicamente, discutir a história dos cursos de Administração da FACE, de maneira conectada ao desenvolvimento da Administração como ciência "americanizada".

Para atender aos objetivos propostos, o trabalho conta com quatro seções, além desta introdução. Na primeira, discutimos as fontes de dados utilizadas para construir a argumentação presente no trabalho e apresentamos algumas referências que tratam da aproximação entre a Administração e a História. Em seguida, abordamos o estabelecimento dos cursos superiores em Administração da FACE/UFMG e discutimos a vinda de um professor estadunidense, Elwyn A. Mauck, para contribuir com a estruturação do curso de Administração Pública e Sociologia e Política da FACE. Em sequência, discorremos sobre a recusa da Faculdade em aderir a acordos estabelecidos com instituições estadunidenses. A dissolução dos cursos de 
Administração na FACE e sua reorganização por meio do currículo do bacharelado em Administração de Empresas são os últimos tópicos abordados na narrativa histórica proposta. Nas considerações finais, indicamos a relevância deste trabalho para o campo e possíveis desenvolvimentos da discussão.

\section{O Resgate da História nos EORs e os Caminhos Percorridos}

Diversos trabalhos vêm se valendo de abordagens históricas a fim de discutir aspectos históricos da Administração. Especificamente em relação ao Brasil, Curado (2001a), Coelho (2006), Vizeu (2008) e Spiandorello (2008), entre outros, buscaram refletir sobre o estabelecimento e desenvolvimento da disciplina por meio de diferentes enfoques. Nesses trabalhos é possível observar uma reorientação na maneira como a história é abordada, reforçando a historicturn ou virada histórica, cuja característica é a aproximação da Administração e, notadamente, dos Estudos Organizacionais com a História, que vem ganhando força desde o início deste século (BOOTH e ROWLINSON, 2006; CLARK e ROWLINSON, 2004; ROWLINSON, JACQUES e BOOTH, 2009), de um ponto de vista que tende a se distanciar dos estudos de matiz rankeana ${ }^{2}$ (ver CURADO, 2001b).

A importância desta abordagem deve-se essencialmente ao seu potencial de permitir conhecer melhor as instituições e organizações. Ao colocar em evidência a História, não intentamos apontar "curiosidades" acerca do estabelecimento da Administração no Brasil, mas lançar luz sobre as bases que constituíram o presente. Acreditamos que a pesquisa histórica pode ampliar a compreensão do desenvolvimento dos cursos de graduação em Administração, bem como de outros atores com potencial de influenciar o desenvolvimento do campo, como o Instituto de Organização Racional do Trabalho (IDORT), cujo papel é discutido por Vizeu (2008), ou das associações de empresários (ZANETTI e VARGAS, 2007).

No campo de Estudos Organizacionais ainda existe a necessidade de consolidar a discussão acerca de sua imbricação com a História. É interessante explicitar ao leitor os construtos e pressupostos teóricos que orientaram o trabalho, já que não se deve pressupor que ele seja capaz de ler nas entrelinhas qual vertente é (ou não) seguida. Contudo, não será esse o caso neste trabalho, já que, em consonância com Alcadipani e Bertero (2012a), a História, aqui, é uma abordagem de pesquisa, mais do que um campo de conhecimento.

Construímos uma narrativa histórica cientes de adotar a noção de narrativa já é um posicionamento entre outros possíveis. Contudo, uma longa e profícua discussão não caberia num espaço secundário deste texto. Por isso, remetemos aos trabalhos de Reed (1996), Carter, McKinlay e Rowlison (2002), Üsdikem e Kieser (2004), Jacques (2006), Weatherbee (2012) que, entre outros, abordam a discussão da aproximação entre Estudos Organizacionais e História, com foco nas diferentes abordagens possíveis na construção desse diálogo.

Para construir esta narrativa consultamos documentos existentes em arquivos da FACE, bem como outros que estavam disponíveis em arquivos online, como os da United States Agency for International Development (USAID), da Organização das Nações Unidas (ONU) e da Fundação Ford. Também pesquisamos nos arquivos da FACE e do Departamento de Ciências Administrativas (DCA, s.d.) cujo conteúdo era de abordagem dos cursos de Administração da Faculdade. Valemo-nos principalmente das atas das reuniões da congregação da Faculdade - citadas como número ordinal da ata, mais RC, mais a data do encontro - e de textos publicados na Revista da Faculdade de Ciências Econômicas (1953-1958).

Além disso, a Lei de Acesso à Informação foi utilizada para requisitar documentos que não estavam presentes nos arquivos da FACE, mas se mostraram importantes na construção do trabalho. Consultamos, ainda, relatórios e memórias escritas por professores que atuaram na construção dos cursos principalmente, e

${ }^{2}$ Leopold Von Ranke é uma importante figura da pesquisa historiográfica de base empírica com cunho positivista. Permanece como uma influência relevante nos estudos históricos. 
também da Faculdade. Salientamos, entre estes, Mauck (1954a), que foi de extrema importância na elaboração deste trabalho.

Ao mesmo tempo, coletamos dados de um conjunto de entrevistas, algumas disponíveis online. As informações presentes nesses diálogos e nos textos foram agrupadas de acordo com os temas abordados, como, por exemplo: a trajetória dos cursos de Administração e o espaço institucional que ocupavam na FACE, a formação de professores, o papel e a atuação dos discentes e bolsistas.

Contudo, pesquisa fundada em documentos tem limitações, especialmente por correr o risco de se estabelecer como uma história chancelada. $\mathrm{O}$ documento sempre encobre ao mesmo tempo em que explicita, e não consegue, obviamente, abarcar a complexidade das relações humanas por inteiro. Assim, em consonância com Foucault (2008 [1969]), vemos o documento como um monumento que guarda informações sobre um passado, mas informações situadas e enviesadas, que devem ser encaradas pelo pesquisador com certa dose de ceticismo. Entretanto, isso não quer dizer que as narrativas sejam recriações do passado, porque, ao contrário, elas são uma perspectiva de um sujeito imerso na história que conta. Além disso, o que resta do passado são narrativas históricas, nunca o passado em si.

Escrevemos este trabalho da perspectiva de que só se faz história do presente. Ao narrarmos nossa versão da história, o passado é visto nos termos do presente. Ou, como afirma Gramsci (2006, p. 37), "[...] escrever história significa fazer história do presente", não apenas porque o presente está ligado ao passado, ainda que não de maneira auto evidente, mas também porque são os interesses do presente que guiam o olhar sobre o passado. Entretanto, isso não quer dizer que o presente seja a justificativa do passado que, além de inapreensível (senão enquanto uma história), não teve suas causalidades determinadas necessariamente por aquilo que pode ser identificado hoje.

Assim, todos os nexos e a razoabilidade que são apresentados aqui foram construídos, não estavam simplesmente dispostos, esperando serem encontrados. Sua compreensibilidade nos termos que apresentamos é fruto do hoje e dos interesses idiossincráticos que moveram os autores deste texto; não visam "justificar" o passado. Isso não quer dizer que os encadeamentos não tenham existido, mas que a apresentação deles na forma como se dá neste trabalho está relacionada às escolhas feitas no próprio momento de se iniciar a análise do objeto que circunscreve os "cursos de Administração da FACE".

\section{A Implantação e o Desenvolvimento dos Cursos de Administração da FACE}

A criação da FACE, em 1941, aconteceu em um momento de intensificação do processo de industrialização de Belo Horizonte e de suas regiões circunvizinhas (PAULA, 1991). A Faculdade surgiu num período de transformação em todos os níveis geopolíticos (local, estadual e nacional), que, ainda que em maior ou menor medida, influenciaram o estabelecimento da Faculdade, e também os cursos que ela ofereceria ao longo dos anos, entre eles os de Administração. A FACE surgiu em um momento no qual Minas Gerais enfrentava dificuldades, já que seu desenvolvimento econômico relativo e, consequentemente, sua influência na federação vinham decaindo ao longo dos anos, ainda que o estado mantivesse parte de seu prestígio político. Esse processo se acentuou com o aumento da importância dos industriais estabelecidos em São Paulo a partir da década de 1930.

Em virtude do crescimento da integração estadual e do fortalecimento do mercado interno, e também dos projetos governamentais para fomentar a industrialização em Minas Gerais, havia a necessidade de formação de mão de obra especializada para atuar nos setores secundário e terciário especialmente. Ao mesmo tempo, os cursos nas áreas econômicas e administrativas eram vistos como elemento capaz de acelerar a modernização da capital mineira, que havia experimentado um rápido crescimento demográfico e contava com pouco mais de 211 mil habitantes à época da fundação da Faculdade, quando tinha menos de cinquenta anos de fundada. A cidade passava por transformações rápidas e crescia de forma acelerada. Nesse contexto 
é possível destacar ainda os planos para a criação de uma cidade industrial nas cercanias da capital mineira e as mudanças urbanas de sentido "modernizante" e industrializante pelas quais Belo Horizonte passava (BAHIA, 2005).

Como várias faculdades que ensinam atualmente Administração, Contabilidade e Economia, a Faculdade de Ciências Econômicas e Administrativas de Minas Gerais (atual FACE) surgiu como instituição anexa a uma Escola de Comércio; a Escola Técnica de Comércio de Minas Gerais. A FACE incorporou os seus cursos e os da Escola de Comércio em 1945, conforme aponta Pinto (1963). Yvon Leite de Magalhães Pinto (1963), ex-diretor da FACE, tendo assumido o cargo no momento em que a Faculdade se estabeleceu com a junção das escolas de comércio, aponta que a reestruturação que extinguiu os cursos de Administração e Finanças foi importante para decidir a criação da nova instituição. O curso existente na FACE foi reestruturado devido às novas diretrizes para cursos superiores de Administração e Finanças, que passaram a vigorar por recomendação do Ministério da Educação e Cultura (BRASIL, 1945):

\begin{abstract}
A integração do curso na categoria do ensino superior, com o acréscimo de exigências e fiscalização mais rigorosa levou os proprietários das duas referidas Faculdades a cogitar da sua extinção ou transferência para terceiros. [...] A 5 de março de 1945 foi organizada, sob a forma de sociedade civil, sem caráter lucrativo, conforme Estatutos, devidamente registrados, a FACULDADE DE CIÊNCIAS ECONÔMICAS E ADMINISTRATIVAS DE MINAS GERAIS, mediante a incorporação da antiga Faculdade de Ciências Econômicas e Administrativas de Belo Horizonte, anexa à Escola Técnica de Comércio de Minas Gerais, e a absorvição da Faculdade de Economia, Administração e Finanças, anexa à Escola Técnica de Comércio de Belo Horizonte. (PINTO, 1963, p. 17-18, grifos no original).
\end{abstract}

Paula (1991) afirma que o período entre 1945 e 1949 marca uma segunda fase da Faculdade de Ciências Econômicas. Nesse momento se iniciou, também, a direção de Yvon Leite de Magalhães Pinto, que durou quinze anos. É também em 1945 que a Faculdade se reorganiza de modo a se estabelecer, em conformidade com a lei que regulou os cursos superiores de Economia, Ciências Contábeis e Atuária, menos generalistas do que o curso de Administração e Finanças até então existente. Essas mudanças marcaram o início de uma etapa de consolidação da Faculdade e de ganho de legitimidade dentro da sociedade mineira, especialmente entre os empresários e sindicatos patronais, que passaram a apoiar ativamente a instituição. É também o princípio de um período no qual a direção da Faculdade consegue estabelecer com maior clareza os rumos que a instituição tomaria.

Mauck (1954a) aponta que, desde que assumiu, em 1945, o diretor Yvon Leite de Magalhães Pinto intentava a implantação de um curso superior de Administração de Empresas, a fim de atender às necessidades do Estado e do setor privado. Não se sabia qual o desenho que se configuraria para os cursos, mas a discussão acerca da importância de lecionar assuntos relacionados à Administração em nível superior fazia-se presente no estatuto da sociedade civil mantenedora da FACE, estabelecido em 1945. Em 1952 foram criados dois cursos, o de Administração Pública e o de Sociologia e Política, que, embora estabelecidos separadamente, na prática funcionavam coligados.

Nos termos da legislação federal, criou a Faculdade um Curso de Administração Pública, nos moldes postos em prática pela Fundação Getúlio Vargas. Já aprovado pelo Conselho Universitário, o novo curso será ensinado em 3 séries [anos], destinando-se ao preparo de profissionais de nível superior para o exercício de atividades administrativas federais, estaduais ou municipais. (CUNHA, 1953, p. 19).

Essa é uma característica a se destacar nos cursos de Administração da FACE e que os diferenciava de outros que surgiriam posteriormente no país durante o espaço de tempo em que a experiência persistiu. Ainda que o curso de Administração Pública tenha sido inspirado pelo ministrado na EBAPE, a existência de um curso de Sociologia e Política, que tinha como foco pensar o Estado e a sociedade por uma abordagem próxima do que é a Ciência Política hoje, foi algo inovador no Brasil e propiciou um ambiente acadêmico enriquecido, 
muito embora tal configuração simbiótica entre os dois cursos tenha permanecido por, relativamente, pouco tempo: quinze anos (1953-1967).

No mesmo ano em que foi estabelecida a criação dos cursos de Sociologia e Política e de Administração Pública, 1952, há registro sobre conversas com a Comissão Mista Brasil Estados Unidos (CMBEU) (ARC, $43^{\mathrm{a}}$, maio de 1952). Aqui é interessante ressaltar que a implantação dos cursos de Administração da FACE quando se buscou e, posteriormente, se recebeu o apoio do governo estadunidense - se inseriam nas políticas do Ponto IV, defendidas por Harry Truman em 1949 como parte da estratégia de defesa dos interesses geopolíticos dos Estados Unidos que era apresentado como o representante do "mundo livre" (sobre isso, ver; ALCADIPANI e BERTERO, 2012a; 2012b; BARROS e CARRIERI, 2013). Neste plano, o ensino de Administração como parte dos programas de transferência de técnicas de "modernização" era visto como um elemento no combate à disseminação do comunismo e das ideias de esquerda. Dessa forma, o estabelecimento dos cursos de graduação no Brasil que contaram com o apoio estadunidense ocorreu em razão da busca pela difusão de certa maneira de gerenciar, adequada a parâmetros estabelecidos nos Estados Unidos, embora inevitavelmente sofressem adaptações. Assim, as escolas de Administração como a FACE eram consideradas relevantes na disseminação não apenas de técnicas de gestão, mas também de princípios que influenciassem o conjunto da sociedade; ou do management,conforme entendem Wood Jr, Tonelli e Cooke (2011).

A CMBEU colocou à disposição dos professores bolsas para estágio nos Estados Unidos. Contudo os docentes da Faculdade não manifestaram interesse. Não há motivos claros para explicar essa recusa. Embora sem mais elementos para fazer uma declaração definitiva, supomos que a idade e a formação do corpo docente, com professores oriundos, muitas vezes, de outras áreas de conhecimento, combinadas à incipiência da carreira acadêmica no Brasil, podem ter ensejado a recusa. O apoio da CMBEU foi solicitado visando outros fins: Yvon Leite de Magalhães Pinto pediu a Orlando M. de Carvalho, à época vice-reitor da instituição e partícipe da comissão, para solicitar à Brazilian Board of Advisorson Public Administration o apoio de um professor estrangeiro. Segundo J. Lyle Cunningham (1954), chefe da divisão de Administração Pública e de Empresas, o pedido foi protocolado no outono de 1952, quando foram iniciadas as negociações com o diretor Yvon Leite de Magalhães Pinto. A vinda do professor estrangeiro tinha por objetivo contribuir com a criação de um Departamento de Administração Pública na Universidade de Minas Gerais como se observa no trecho a seguir:

O Diretor da Faculdade de Ciências Econômicas da Universidade de Minas Gerais, com inteiro apoio do Reitor da Universidade, está extremamente interessado na criação de um departamento de Administração Pública naquela Faculdade, tendo porém demonstrado que se tornam necessários os serviços de um professor competente e experimentado nesse setor, a fim de organizar e inaugurar o departamento, bem como acompanhar suas atividades durante pelo menos um ano. Nessas condições, submeteu ele um pedido oficial datado de $1^{\circ}$ de dezembro de 1952, no sentido de que o Governo dos Estados Unidos, através do Ponto IV, fizesse vir ao Brasil um professor capaz de se encarregar da tarefa. Esse especialista servirá à Universidade de Minas Gerais, durante um ano letivo completo, formulará o programa de Administração Pública, servirá como Diretor do Departamento respectivo e ministrará os cursos não só de Administração Pública Geral como Municipal. Esse projeto, tendo sido aceito a 9 de dezembro de 1952 pela Comissão Consultiva e aprovado pela Comissão Mista Brasil-Estados Unidos de Desenvolvimento Econômico a 29 de dezembro de 1952 foi submetido pelo Diretor de Cooperação Técnica do I.I.A.A., a 20 do mesmo mês. Em virtude da aprovação do I.I.A.A, deverá o aludido professor chegar a Belo Horizonte no mês de julho de 1953 para cumprimento de sua missão. (BRASIL, 1953, s.p.). 
Em decorrência do acordo de cooperação entre Brasil e EUA, inscrito sob o Ponto IV, o professor Elwyn A. Mauck chegou à instituição em meados de 1953. O acordo e suas motivações podem ser descritos da seguinte maneira:

O programa de treinamento em Administração Pública na Universidade de Minas Gerais, Brasil, foi estabelecido como resultado de um projeto assinado em 12 de junho de 1953 entre Merwin L. Bohan, diretor de cooperação técnica no Brasil e Yvon Leite de Magalhães Pinto, diretor da Faculdade de Ciências Econômicas da Universidade de Minas Gerais. O acordo declarou que a universidade desejava criar e conduzir um departamento de Administração Pública desde 1945, uma vez que o corpo docente da instituição acreditava que o estabelecimento de tal departamento atenderia não apenas uma necessidade de Minas Gerais, mas, ao servir de exemplo, estimularia desenvolvimentos similares em outras universidades brasileiras. (MAUCK, 1954a, p. 5, grifos nossos, tradução livre).

No Repportto Congressonthe Mutual Security Program, de 1953 (WHITE HOUSE, 1953, grifos nossos, tradução livre), lemos que:

O Comitê Brasileiro de Conselheiros em Administração Pública é o principal órgão responsável pelos aperfeiçoamentos na Administração Pública no Brasil. Técnicos dos Estados Unidos estão trabalhando com o Comitê Brasileiro em vários estudos sobre Administração Pública, [...] e o estabelecimento de uma escola e um instituto de administração na Universidade de Minas Gerais em Belo Horizonte.

Mauck (1954a) aponta que a ideia de um curso de Administração para a área pública era desenvolvida na FACE desde a segunda metade da década de 1940. Pode ser que a intenção só tenha sido passível de ser efetivada quando o curso da EBAPE foi criado e pôde servir de modelo para a escola. Desde o princípio do projeto, o diretor e outros membros da Faculdade viram a necessidade de trazer um especialista para contribuir com a construção dos cursos:

A fim de obter assistência técnica a faculdade solicitou inicialmente a vinda de dois professores estadunidenses que foram convidados ao Rio de Janeiro pelas Nações Unidas, a fim de que eles pudessem analisar e fazer recomendações em relação ao plano de estudos de administração. Pouco depois da visita dos professores e de ter recebido as recomendações, a faculdade assinou um contrato com o Office of Inter-American Affairs [...] no qual ficou acordado o envio de um professor de Administração Pública pelo período de um ano. (MAUCK, 1954b, p. 76).

É possível que os professores convidados pela FACE estivessem no Rio de Janeiro para apoiar a implantação da EBAPE (dada a coincidência de datas com a implantação daquela escola). De toda maneira, o professor, que posteriormente foi a Belo Horizonte para atuar como consultor era o próprio Mauck e não se limitou a discutir assuntos estritamente ligados ao curso. Propôs cursos também de curta duração que atenderiam os servidores públicos e as autoridades governamentais, além de ter indicado títulos para a biblioteca e ministrado aulas (MAUCK, 1954a; 1954b). Sugeriu, ainda, alterações no curso que foram registradas e adotadas pela instituição, como a mudança, na duração do curso, de três para quatro anos e a inserção de algumas disciplinas $\left(58^{\mathrm{a}} \mathrm{RC}, 07 / 12 / 1953\right)$.

Importante destacar que, conforme mencionado, o curso de Administração Pública era acoplado ao curso de Sociologia e Política - seus currículos aparecem conjuntamente nos documentos consultados. Mauck (1954a) salienta que, na prática, essa coligação dos cursos cumpria um papel estratégico na Faculdade: dar legitimidade ao curso de Administração Pública. Uma vez que tal curso não era reconhecido oficialmente e que o profissional graduado não teria titulação formal, uma saída encontrada pela universidade foi estimular 
e facilitar a matrícula concomitante em ambos os cursos - isso porque o curso de Sociologia e Política graduava alunos que teriam o título formalmente reconhecido.

Cursos não podem ser ofertados e lecionados na Faculdade sem tal aprovação, mas os graus ou diplomas obtidos pelos estudantes que escolheram o programa composto destes cursos [de Administração Pública] não tem status de graduado no momento em que buscam por emprego. Como solução provisória, a Faculdade assegurou uma legalidade para seu currículo em Sociologia e Política, mas não tentou fazer o mesmo para seu currículo em Administração Pública. Atualmente, os estudantes estão matriculados sob os dois currículos. Assim, eles têm a vantagem de buscar um diploma reconhecido ao mesmo tempo em que atendem ao curso de Administração Pública, que ainda está em processo de formulação. Quando a escola acreditar que não haverá mais modificações no currículo de Administração Pública, ela planeja buscar tomar as medidas necessárias para formalizar o programa. (MAUCK, 1954a, p. 13, tradução livre).

Observamos no trecho anterior que, na visão de Mauck (1954a), a solução de coligar os cursos de Administração Pública e Sociologia e Política era temporária e seria superada assim que o currículo mínimo da disciplina fosse aprovado, o que aconteceu apenas em 1966, quando o curso de Sociologia e Política já havia sido movido da faculdade, como se verá adiante.

Para Keinert e Silva (2010), o estabelecimento de um curso de Sociologia e Política, em conjunto com os cursos de Administração Pública, de Administração de Empresas, Economia e Contabilidade, pode ser considerado uma inovação importante da FACE. Os autores apontam que, contando com uma formação pragmática e com a influência que aquelas áreas tinham no currículo, a Faculdade tornou-se uma importante fornecedora de quadros para a burocracia pública de Minas Gerais. Buscava-se estabelecer uma Administração Pública muito mais próxima da Sociologia e da Ciência Política do que das áreas relacionadas à gestão de negócios (MAUCK, 1954a; 1954b). Como se verá adiante, essa orientação, que se distancia daquela que se tornou dominante no campo posteriormente, levou a represálias os cursos de Administração Pública e de Sociologia e Política, culminando com sua eliminação da FACE. Mauck (1954b) não via problemas na solução encontrada para a Faculdade: o funcionamento integrado dos cursos de Administração Pública e Sociologia e Política. O autor defendia que, na maioria dos casos, a Administração Pública estava ligada à Ciência Política, entendimento distinto daquele que veio a justificar o encerramento do curso de Administração Pública em 1968. Além disso, essa compreensão também diverge da postura que se tornou dominante e foi exportada pelos EUA a partir do fim da década de 1950.

$\mathrm{O}$ diretor e os membros da faculdade, utilizando de conhecimentos adquiridos mediante estudos no exterior e utilizando também de todos os recursos disponíveis localmente, desenvolveram dois novos [...]. O primeiro programa recebeu o título de Sociologia e Política, e o segundo foi nomeado de "Administração". O projeto da faculdade ao estabelecer estes dois novos planos de estudo era adaptar ao Brasil os conceitos mais novos dos estudos sociais que foram desenvolvidos com muito êxito na França, Inglaterra e Estados Unidos. (MAUCK, 1954b, p. 75, grifos nossos, tradução livre).

Os esforços de Mauck contribuíram para que os cursos de Administração Pública e Sociologia e Política funcionassem em conjunto. Siqueira (2012, em entrevista), ex-aluna dos cursos de Sociologia e Política e Administração Pública, ressalta:

Na verdade, os dois cursos eram um só. Ao cursar uma mesma grade disciplinar, apenas com a introdução de umas poucas - duas? - disciplinas, obtínhamos os dois diplomas. Analisando a proposta, ainda hoje reconheço que não se pode falar em gestão pública a não ser com um referencial sociológico e principalmente político. 
O plano era adaptar a Administração aos estudos sociais e, não, aos estudos administrativos. O consultor estadunidense chegou a afirmar que "[...] os cursos de Administração Pública devem se basear integralmente no programa [curso] do novo departamento de Sociologia e Política" (MAUCK, 1954b, p. 80). Além disso, a preponderância que estes cursos adquiriram dentro da Faculdade, em conjunto com o curso de Economia, mostra que a estruturação realizada obteve sucesso ao estabelecer uma área que se consolidou rapidamente na FACE. Mauck (1954b, p. 75, tradução livre) afirma que "[...] somente mediante os esforços constantes e incansáveis do diretor professor Yvon de Magalhães Pinto foi possível superar os obstáculos [colocados pela universidade e pelo Governo Federal] e os dois novos cursos entraram em vigência em 1953".

O curso de Administração de Empresas, ou "Administração de Empresa" conforme a grafia da época, foi aprovado em 11 de novembro de 1954 (61 ${ }^{a}$ RC01/06/1954). Para a sua consolidação havia a promessa, não realizada, da vinda de dois professores "americanos", que seriam custeados pelo Instituto de Negócios Interamericanos. Ficou também em aberto a vinda, que não ocorreu, de um professor italiano. Mauck (1954a, p. 16) aponta que também teve participação no delineamento deste curso:

O diretor da Faculdade fez outro pedido de assistência ao professor estadunidense [Mauck]. Ele requereu auxílio no planejamento de um programa de formação em administração de empresas. As recomendações posteriormente preparadas para serem submetidas a ele não estão incluídas aqui porque estão além do escopo deste relatório e podem constituir a base de um acordo para um projeto separado no futuro.

Ou seja, pelo menos a princípio, a FACE contava com um projeto para o curso de Administração inspirado por um consultor estadunidense. Assim, é de se imaginar que tal curso estaria adequado às formas "modernas" que vinham sendo assumidas nos EUA, embora a expertise de Mauck estivesse mais ligada à Administração Pública. O esforço em subsidiar os estudos dos alunos se dava também como tentativa de solucionar aquilo que Mauck (1954a; 1954b) e Taylor (1968) apontavam como uma grande dificuldade para o ensino no Brasil se tornar mais similar aos modelos estadunidenses: a pequena quantidade de alunos que poderiam se dedicar integralmente aos estudos.

Some-se que, além da presença de Elwin A. Mawck para lecionar no curso de Administração Pública,poucos dos outros docentes poderiam ser considerados de posse de conhecimentos referentes ao campo específico da Administração Pública, da Sociologia ou Política ou da Administração de Empresas na faculdade. Assim, novas demandas foram criadas em relação à formação do quadro de professores da FACE. Para lidar com essa situação, a Faculdade estabeleceu iniciativas que permitiriam superar algumas das deficiências percebidas. Segundo Mauck (1954a), ele colaborou, a pedido do ex-diretor Yvon Leite de Magalhães Pinto, na elaboração de um programa de bolsas que, depois de estabelecido com apoio de empresários mineiros, tornou-se modelo nacionalmente (PINTO, 1963).

Contudo, segundo José Alberto Magno de Carvalho (2012, em entrevista), era pequena a presença, entre os bolsistas, de alunos ligados aos cursos de Administração, especialmente daqueles relacionados ao curso de Administração de Empresas.

[...] do lado da Administração, naquela época, no início, havia alguns bolsistas em tempo integral da Administração. Depois foi esvaziando, esvaziando e acabou que na minha época [1961 a 1964] de bolsista - eu fui bolsista - havia só um ou dois de Administração, mais ligados à Administração Pública. Então o que parece [...] é que o curso de Administração não valorizava muito a parte acadêmica.

Sem a efetivação de outros acordos, a FACE teve de contar apenas com programas internos de formação de docentes e de apoio à pesquisa. Após a implantação dos cargos de assistente de ensino e pesquisa e do programa de bolsas, a Faculdade passou a contar com um número razoável de pessoas que se dedicavam a 
estudar as disciplinas que ministrariam. Entretanto, a formação desses novos professores se dava de forma precária:

\begin{abstract}
Éramos todos autodidatas, porque os professores também não sabiam quase nada; a partir do segundo ano, já sabíamos mais do que a metade deles. [...] ser bolsista me marcou muito, pois foram quatro anos de tempo integral no meio de um grupo de gente super intelectualizada, que se automotivava, criava seus próprios valores e estudava por iniciativa própria. Nos primeiros anos, estudávamos em livros franceses, que comprávamos por conta própria; nos últimos anos estudávamos todos em livros americanos. Os professores sequer liam em inglês. (CASTRO, 2002, p. 85-86).
\end{abstract}

Essa estratégia, que também permitia contornar um pouco do poder exercido pelos catedráticos e contribuía para a renovação do curso e o arejamento dos debates, não atendia às novas demandas que vinham se estabelecendo para a formação de professores de nível superior. Mas, não apenas por isso. Já no final da década de 1950 percebe-se que a Faculdade espelha-se na EAESP, cujo desenvolvimento apoiava-se na formação de professores nos Estados Unidos, bem como na presença de professores estadunidenses, além de contar com recursos da Fundação Ford para consolidar o modelo no qual vinha se inspirando.

\title{
O (Des)acordo de 1959, e a Unificação dos Cursos de Administração da FACE
}

Durante a década de 1950, o professor Yvon Leite de Magalhães Pinto, em nome da Faculdade, estabeleceu conversas com a Michigan State University a fim de criar uma parceria para o aprimoramento do pessoal e do ensino ministrado. Em janeiro de 1955, a FACE pediu por apoio de uma missão dos EUA para que pudesse estabelecer o curso de Administração de Empresas, possivelmente estimulada pela presença de professores estadunidenses para a implantação da EAESP. Dois professores foram enviados à escola em fevereiro do mesmo ano. Em 1956, a FACE pediu apoio à FGV para aprimorar seu curso de Administração de Empresas. Em novembro do mesmo ano, um professor de Marketing da EAESP e um estadunidense foram a Minas Gerais para um curso de Marketing de uma semana, apoiado pelas associações comerciais do estado. Já em maio de 1957, professores dos EUA e da FGV estiveram na FACE para uma visita. Em junho de 1957, ficou decidido que seriam enviados professores dos EUA à FACE, tendo ocorrido visitas à faculdade durante o ano. Ainda em janeiro de 1957, no dia 23, cinco professores da UFMG visitaram a EAESP para compreender como se dava o funcionamento do curso naquela escola. Estas informações são trazidas por Taylor (1968).

Como se percebe, os Estados Unidos, por meio da Universidade de Michigan e a FGV, via EAESP, foram pontos de apoio reiteradamente procurados pela FACE para estabelecer os seus cursos. Isso indica o poder de atração do modelo de ensino estadunidense e sua capacidade de disseminação para uma instituição como a FACE, situada num país e num contexto particular de pouca tradição acadêmica. Essa condição era verificável especialmente no novo campo do ensino superior em Administração, tema que historicamente era abordado de um ponto de vista prático-empírico, com pouca sofisticação teórica.

Em 1959, a FACE foi convidada a participar do mesmo acordo que beneficiou os cursos de Administração da UFRGS, UFBA, EBAPE e EAESP, mencionado por Fischer (1985) e denominado de PBA-1. O acordo promoveu um modo específico de ensino de Administração, baseado nos modelos elaborados nos Estados Unidos, especialmente durante a década de 1950, e serviu como parte importante da política estadunidense de disseminação do management. Contudo, a FACE, que se antecipara a esse acordo, interrompeu as negociações em 1957, como mostra Taylor (1968). Posteriormente, elas foram retomadas, mas novamente 
rompidas, como mostra um telegrama de Claude McMillan $\left(1959^{3}\right)$ recolhido na Universidade de Michigan, que aponta que a Universidade de Minas Gerais não só estava fora "de novo" como também deveria ser ignorada nos planos tratados, naquele momento, para fornecer apoio técnico a universidades brasileiras.

Na $90^{\text {a }} \mathrm{RC}$, de fevereiro de 1959, afirma-se:

Disse o senhor Diretor [Yvon Leite] que a Faculdade fora convidada a participar de um convênio com o Ponto IV para o ensino de Administração Pública e de empresa. As bases desse convênio no entanto não atendiam aos interesses da Faculdade, não tendo sido aceitas.

Nessa mesma reunião, o diretor afirmou que vinham se ampliando os laços da instituição com outras entidades nacionais e estrangeiras, como a Universidade de Porto Rico, apontada por Elwyn A. Mauck como um dos possíveis destinos para intercâmbio docente e discente em 1954. As informações presentes nos documentos não permitem avaliações sobre possíveis acordos propostos, nem sobre a visita em si. Entretanto, existem mais informações sobre a rejeição do acordo com os EUA. Transcrevemos um trecho de carta endereçada a Ruben Austin, coordenador do projeto de apoio aos cursos de Administração no Brasil. Não fica claro o autor da carta coletada nos arquivos da Universidade de Michigan e datada de 16 de junho de 1959 (grifos nossos):

O [...] diretor Ivan [sic] se recusou a assinar o acordo, solicitando uma reformulação da alteração que tinha sido realizada visando acomodar sua assinatura. O Rio [?] concordou em reformular a emenda ligeiramente, e convidou-o para voltar na semana seguinte. $\mathrm{O}$ diretor Ivan [sic] não voltou, mas enviou uma carta ao ICA / Rio afirmando vigorosamente que todo o plano tendia a subordinar sua escola ao EAESP e à EBAP, e que ele não poderia se juntar sob estas circunstâncias. Ficamos surpresos, claro, uma vez que ele havia sido avisado de que o Presidente Kubitschek o instruiu a se juntar ao grupo. [...] Eles [ICA/Rio] estão retomando suas negociações com a Universidade do Brasil no Rio de Janeiro. [...] Herder, ao que me lembre, não achou que devia ser tomada uma atitude tão drástica, mas também era cético. Mac Millan confiava plenamente que a UMG poderia ser trazida de volta para se tornar uma participante [...]. Os desenvolvimentos posteriores tornaram evidente que teríamos feito bem ao deixar a UMG de fora meses atrás. Assim, as negociações estão em andamento mais uma vez com a Universidade do Brasil.

Embora haja a menção sobre a escolha da Universidade do Brasil para substituir a FACE, isso não ocorreu. Taylor (1968) aponta que se optou pela escola estabelecida na capital de Pernambuco, embora esse acordo também não tenha se efetivado devido à oposição principalmente dos estudantes. Apenas os cursos das universidades federais do Rio Grande do Sul e da Bahia e aqueles ligados à fundação Getúlio Vargas receberam o apoio oferecido por esse acordo. Isso não quer dizer, contudo, que apenas esses cursos foram influenciados pelo modelo estadunidense de ensino da Administração. O curso de Administração que sucedeu aos cursos de Administração Pública e de Empresas foi criado profundamente inspirado pelo seu congênere da EAESP; até por força legal, já que o currículo mínimo do curso de Administração, aprovado em 1966, foi bastante influenciado pela EAESP, que, por sua vez, seguia o modelo de ensino estadunidense, ainda que com adaptações e especificidades (ALCADIPANI e BERTERO, 2012b). A razão para a desistência da FACE, informada por Yvon, era a posição subordinada em que a Faculdade que dirigia seria colocada. Isso de fato ocorreria, pois, como afirmam Taylor (1968) e Alcadipani e Bertero (2012a), a ideia era utilizar as escolas da FGV como centros para disseminar o management para outras escolas, que, por sua

\footnotetext{
${ }^{3}$ Claude McMillan. Telegrama para o líder do projeto. 13 de junho de 1959. Cortesia do professor Bill Cooke. O remetente da mensagem era 0 chefe da missão técnica no Brasil, com sua designação disponível em <http://spartanhistory.kora.matrix.msu.edu/files/3/15/3-F-199-56-JUNE\%2013\%201958.pdf> Acesso em: 19 out. 2012.
} 
vez, contribuiriam com sua disseminação na região em que se inseriam. Chama a atenção a menção ao pedido direto do presidente Juscelino Kubitschek para que Yvon aceitasse o acordo, o que é plausível considerando que aquele participava como vice-diretor do Conselho Administrativo da FACE quando de sua fundação e Yvon foi escolhido para seu primeiro mandato (PAULA, 1991).

Há, ainda, outro elemento que não contradiz a desistência da FACE em uma disputa por prestígio, e pode ter facilitado ou encaminhado para essa tomada de posição. $O$ ano em que se efetivou a desistência definitiva da FACE das conversações, 1959, permite indagar se as relações com o corpo estudantil não influenciaram a decisão do diretor. Como apontam Siegel (2010) e Taylor (1968), a presença estadunidense causava desconforto nas outras escolas, o que culminou com o curso de Administração da Universidade de Pernambuco deixando o acordo após diversas manifestações contrárias, notadamente do corpo estudantil da universidade (SIEGEL, 2010).

À época, a FACE contava com um movimento estudantil bastante ativo e isso pode ter contribuído para que a pressão dos estudantes fosse mais um elemento à obstrução do acordo. Também Carvalho (2012, em entrevista) acredita que este foi fator chave para que o curso desistisse de participar dos acordos de 1959. Carvalho (2012, em entrevista) afirmou que, em um ambiente altamente politizado e atravessado pelo nacionalismo de um lado a outro do espectro político, a assinatura de um acordo com uma instituição estadunidense poderia ser muito mal vista. Além disso, uma vez que a disseminação do management era reconhecida pelos próprios Estados Unidos como de importância geopolítica, a rejeição aos acordos por parte relevante do corpo estudantil passa a fazer ainda mais sentido.

Assim, acreditamos que o rompimento das conversas sobre uma possível ajuda estadunidense à FACE se deu pela conjunção de pelo menos dois fatores: a insatisfação de parte do corpo discente em relação à atuação de um mecanismo que proporcionaria um canal institucional para a influência estadunidense na FACE, aliada à rejeição de uma posição subordinada em relação à FGV, que foi a alegação dada por Yvon Leite de Magalhães Pinto.

Entretanto, o curso de Administração Pública já havia sido criado em 1952 sob a sombra da EBAP e ficou registrado na reunião da congregação, de dezembro de 1957 (87 $\mathrm{RC}, 10 / 12 / 1957)$, que ocorreram alterações no currículo do curso de Administração de Empresas, visando a que este ficasse com a mesma formatação de seu correlato da EAESP. Além disso, Mauck (1954a) já havia mencionado um acordo futuro envolvendo a FACE e instituições dos EUA, o qual parecia ir ao encontro não apenas das necessidades e dos anseios da Faculdade, mas também dos interesses estadunidenses em disseminar certo modelo de ensino em Administração como arma ideológica no contexto da Guerra Fria.

Embora tenha se retirado do acordo com os EUA, mediado pela FGV e pela Universidade de Michigan (ACADIPANI e BERTERO, 2012a), a FACE permaneceu partícipe no processo de institucionalização dos currículos de Administração. Isso ficou demonstrado em um trecho do parecer do Conselho Nacional de Educação, de 1960, que ratifica a mudança de currículos nos cursos de Administração Pública, Sociologia e Política e Administração de Empresas da FACE (MEC, 1960, s.p.): “[...] sejam considerados os presentes currículos como padrões básicos oficiais para os respectivos tipos de ensino, com vistas a autorizações e reconhecimentos que venham a ser pleiteados por outras instituições".

Contudo, o trecho "padrões básicos oficiais" foi riscado, tendo sido sobrescrita a expressão "fase de estudo", o que pode indicar que estavam em discussão quais seriam as bases para o currículo de pelo menos um dos cursos analisados no parecer (possivelmente mais que um). Encontramos evidências de que a FACE fez diversas sugestões de disciplinas ao currículo mínimo do curso de Administração, no ano de 1962, como mostra o livro de documentos do Departamento de Ciências Administrativas (DCA, s.d.). Assim, apesar de ocupar um espaço marginal nas narrativas sobre a história da Administração no país, os cursos da FACE foram ativos nos diálogos acerca do estabelecimento dos currículos mínimos em Administração, que acabaram por chancelar o modelo que vinha sendo desenvolvido na EAESP. 
Mesmo na FACE o curso de Administração de Empresas não ocupava um lugar de destaque. Esse lugar secundário pode ser depreendido de uma carta enviada, em 05 de julho de 1963, por seus alunos de Administração ao Colegiado da Faculdade. Nela denunciavam que a Faculdade era omissa na divulgação do curso. Atestavam eles, ainda, que "[...] já não bastasse o nome da Faculdade que obscurece todos os demais cursos, com exceção de Economistas", não havia promoção dos outros cursos, especialmente o de Administração de Empresas. Esse sentimento de que o curso de Administração de Empresas era relegado no interior da Faculdade parecia ser relativamente compartilhado, e de acordo com a maior parte do material colhido nas entrevistas. Na reunião de julho de 1963, os alunos ameaçam lançar uma campanha, aparentemente não realizada, para sua separação em outra faculdade (de Administração Pública e de Administração de Empresa), em virtude do descaso da Faculdade para com os cursos de Administração e Contabilidade. Além disso, os alunos se queixavam do excesso de faltas dos professores do curso e excesso de aulas teóricas. Apontaram, ainda, a baixa quantidade de bolsas para o curso de Administração de Empresas, atestando que os bolsistas "ficavam abandonados à própria sorte", com apenas um professor contratado em tempo integral para a área do total de quinze existentes então (146 ${ }^{\mathrm{a}} \mathrm{RC}$ 05/07/1963). Em sua resposta, o Departamento subscreve a maior parte da reclamação dos alunos apontando que o curso de Administração de Empresa "é orientado no sentido de formação de técnicos", o que se alinha ao nome dado à profissão de Técnico em Administração, a função então exercida pelos egressos dos bacharelados em Administração. Cada um dos dois cursos de Administração da universidade tinha espaços diferentes entre si, um com uma carga teórica mais robusta e outro de viés mais prático.

Assim, o curso, que tinha valor estratégico na visão dos ideólogos estadunidenses da Guerra Fria e na agenda do Ponto IV, ocupava na FACE uma posição subordinada em relação ao seu congênere que abordava o conhecimento considerando suas implicações políticas, perspectiva que é, em geral, rejeitada pelo management. Nesse sentido, tendo em vista a posição do curso de Administração de Empresas na própria faculdade, não é de espantar que ele tenha sido ofuscado em âmbito nacional e recebido pouca atenção de outros atores institucionais, especialmente após a rejeição dos acordos de 1959.

Contudo a situação dos cursos na Faculdade passa a se inverter após o golpe militar de 1964. Nesse momento a posição do curso de Administração de Empresas altera-se gradativamente e ele vai adquirindo mais centralidade, até absorver o curso de Administração Pública no período posterior ao qual o curso de Sociologia e Política fora transferido para a Faculdade de Filosofia e Ciências Humanas da UFMG (1966). Dulci (1990, p. 123) aponta que "[a]pós 1964, o treinamento em Economia e Administração de Empresas confere grande prestígio para o acesso às posições tecno-empresariais". Além disso, o caráter técnico atribuído ao curso de Administração de Empresas, em detrimento de abordagens vistas como "políticas", colocava-o em posição vantajosa em relação aos outros cursos de Administração da FACE. Carvalho (2007, p. 6-7) aponta que houve uma mudança em relação ao perfil do estudante bolsista no momento que sucedeu ao golpe:

[...] na faculdade [...] [atuava] toda a base fortíssima de lideranças estudantis no Brasil. Interessantemente os grupos políticos de esquerda escolhiam [...] seus jovens mais promissores e mandavam eles $[$ sic $]$ fazerem o curso de Sociologia $[. .$.$] aqui. E esses líderes$ [...] quase todos eles eram bolsistas.

Carvalho (2007) aponta que, após o golpe de 64, a atuação política ganhou preponderância em relação à dedicação aos estudos. Ao mesmo tempo, atividades consideradas "antiamericanas" foram punidas na FACE no momento em que Peter Bell, representante da Fundação Ford, foi visitar a Faculdade. Em dezembro de $1964,{ }^{4}$ um aluno foi suspenso por oito dias por ter escrito em um quadro "Abaixo aos vendidos da Ford Foundation". O relatório que recomendou a punição do aluno foi fruto de sindicância instaurada após

${ }^{4}$ Ata da $161^{\text {a }}$ Reunião da Congregação da FACE, 9 de dezembro de 1964. 
denúncia realizada por um professor da Faculdade. Bell (2012, s. p.) atesta que a hostilidade recebida quando esteve na FACE foi um momento marcante em sua carreira.

Peter Bell havia ido à FACE recrutar egressos do curso de sociologia e política para fazer cursos "adequados" à maneira estadunidense de fazer Ciências Sociais, num movimento de conformação parecido com aquele que se viu também em relação à Administração. Cohn $(2006$, p. 80) aponta que "[...] a ideia da modernização das Ciências Sociais nesse período de horror que foi a Guerra-Fria, na segunda metade do Século XX, significava introduzir no Brasil, através de ações institucionais, o que se produzia nas universidades de origem anglo-saxônica". Keinert e Silva (2010) afirmam que a experiência de convivência entre os cursos de Administração Pública, Administração de Empresas, Ciências Contábeis e Atuariais e Ciências Econômicas foi determinante para que a Fundação Ford se interessasse em investir na formação de acadêmicos da área de Ciência Política, cujo primeiro curso foi instaurado na UFMG pelos egressos dos cursos de Sociologia e Política e Administração Pública, em 1966.

Na $161^{a}$ RC (09/12/1964), foi discutido se o curso de Sociologia e Política não deveria ser transferido para a Faculdade de Filosofia, onde já havia um curso de Sociologia e maior afinidade de temas. Mas não era disso que se tratava. A questão era, principalmente, mudar o perfil dos integrantes da Faculdade. A ata registra que o motivo da transferência do curso seria o fato de os "agitadores" estarem, em sua maioria, ligados a esse curso, ainda que também houvesse em outros. De fato, a última entrada para o curso de Sociologia e Política foi nesse mesmo ano, conforme Reis (2002), e para o curso de Administração Pública em 1965. Cabe salientar que nesse momento já haviam acontecido expurgos na faculdade, com professores e alunos expulsos ou sob vigilância. Dessa forma, os professores da FACE se empenharam em tornar o corpo discente da Faculdade mais dócil e homogêneo, visando se livrar daqueles considerados indesejados.

Assim, na FACE, há um processo de desestruturação do curso de Administração Pública e Sociologia e Política, que era um curso singular no Brasil, em concomitância com a consolidação da ditadura militar. O desmonte do curso se deu em favor da reestruturação do curso de Administração de Empresas, que serviu de base para o curso de Administração, estabelecido em 1968. O curso manteve as bases da graduação em Administração de Empresas e substituiu o bacharelado em Administração Pública, mantendo apenas algumas disciplinas optativas (RODRIGUES e LUZ, 1981). Nesse sentido, a FACE ficou mais próxima do paradigma do management que entende a Administração como um conjunto de pressupostos universalizáveis, em geral inspirados em conhecimentos construídos alhures, especialmente nos Estados Unidos.

O curso de Administração Pública também deixou de ser citado nas atas da congregação em 1966,embora só tenha sido extinto formalmente dois anos depois. Em 1967, a FACE deixou de abrigar o curso de Sociologia e Política, elemento que lhe conferia certa distinção entre unidades equivalentes em outras universidades do Brasil (PAULA, 1991). Em 1968, por fim, os cursos de Administração Pública e de Administração de Empresas deram lugar a um só curso de Administração, herdeiro direto do curso de Administração de Empresas. É interessante transcrever o trecho do parecer que defendeu a extinção do curso de Administração Pública:

Embora sem estar convencidos da conveniência de manter-se um curso de Administração Pública em nível de graduação, os professores-signatários detiveram-se, também, no exame da questão. A conclusão a que chegaram é a de que o curso em apreço deverá ter por base o curso de administração de empresas proposto, incorporando-se a ele algumas disciplinas especificamente relacionadas com o setor público (FACE, 1968).

José Alberto Magno de Carvalho (2007) aponta que a transferência dos cursos de Sociologia e de Ciência Política para a Faculdade de Filosofia e Ciências Humanas foi uma perda para os cursos e para a FACE. Carvalho (2012, em entrevista) afirmou, ainda: "No fundo, no fundo, o argumento formal era válido, mas a saída daqui [da FACE] [...] foi logo depois do golpe. Foi muito mais por razões ideológicas [o pensamento parecia ser]: 'Eles eram muito esquerdistas e tinha que tirar daqui'”. Com isso, houve uma reconfiguração 
das orientações políticas dentro da FACE, que poderia ser verificada numa pesquisa que se estendesse para um período além do contemplado aqui.

Contudo é certo afirmar que durante o período discutido, o estabelecimento e o desenvolvimento dos cursos em Administração da FACE se deram em um ambiente de conflito entre diferentes ideologias. Entre outras coisas, havia visões distintas sobre o desenvolvimento do país e de suas instituições. Além disso, enquanto os cursos de Administração Pública e Sociologia e Política conviveram com os demais cursos da FACE, inclusive o de Administração de Empresas, havia disputas que concerniam ao espaço ocupado pela teoria e pelos próprios cursos no interior da Faculdade. Ao final do período estudado, os cursos de Sociologia e Política e Administração Pública, que traziam maior especificidade ao cenário do ensino de Administração na FACE, foram encerrados e substituídos por um curso de Administração que se referenciava no currículo mínimo e nas proposições da EAESP, aproximando-se então do modelo que os Estados Unidos visavam disseminar.

\section{Considerações Finais}

Neste artigo buscamos apresentar uma narrativa sobre o estabelecimento e os primeiros dezesseis anos dos cursos de Administração da FACE. Acreditamos que o artigo traz uma contribuição para a área na medida em que lança luz sobre a história de uma escola que, em geral, ocupa espaços marginais em outras narrativas sobre a constituição da Administração no Brasil, embora tenha sido uma das pioneiras no estabelecimento dessa modalidade de ensino superior no país. O motivo pelo qual essa história é silenciada reflete aspectos geopolíticos, mas também certa disposição de poder que perpassa a academia e legitima alguns espaços enquanto desconsidera outros. Dada a importância das escolas de Administração para a disseminação do management, para além de seu caráter técnico, a contribuição está na compreensão do quadro geral da disciplina e de seus efeitos no país.

Com base na discussão apresentada, salientamos três pontos específicos do trabalho que, acreditamos, podem fomentar futuras discussões. Um deles é a participação de um estadunidense no estabelecimento dos cursos de Administração da FACE - um aspecto que não aparece nas discussões cujo tema é a investigação dos cursos da época, especialmente a catalogação feita por Machado (1966). O segundo é a rejeição sofrida pelos acordos assinados em 1959, devido à participação dos EUA e à centralidade ocupada pelas escolas da FGV, elas mesmas consideradas reprodutoras do modelo estadunidense, ainda que com adaptações, conforme indicam Alcadipani e Bertero (2012a; 2012b). O terceiro, a reestruturação dos cursos da faculdade em concomitância ao estabelecimento da ditadura militar no Brasil, é um aspecto que nos alerta para conexões entre o saber e seu ambiente político. Conexões estas que muitas vezes não se dão no campo da restrição ou promoção de certas ideias e posicionamentos, mas que se concretizam em ações violentas contra indivíduos e as instituições que os abrigam. Nesse sentido, ainda estão por serem discutidas as relações dos sucessivos regimes repressivos brasileiros com a Administração estudada e praticada no país.

Discutir o desenvolvimento de um curso superior em administração brasileiro que recebeu atenção e apoio estadunidense para se desenvolver, mesmo estando fora do Rio de Janeiro e de São Paulo, capitais brasileiras que hegemonizavam o ambiente econômico e político da época, mostra que o estabelecimento do ensino superior em Administração no Brasil não pode ser visto como algo "natural". Contudo, tampouco há indícios de que o processo tenha sido unívoco ou unidirecional, sendo necessário, ainda, considerar as complexas relações que se estabelecem entre "teoria" e "prática". Relações que não advêm da determinação de um polo pelo outro, mas se constrói na inter-relação entre ambos.

O recorte temporal escolhido, embora pequeno se considerarmos que em 2013 completaram-se 60 anos de ensino em Administração na FACE, atende aos objetivos do trabalho. Além disso, permite ainda a ênfase no momento de estabelecimento do ensino na disciplina e evita abarcar períodos muito distintos, uma vez que, poucos anos depois do estabelecimento de um só curso, a Faculdade inaugurou seu curso de mestrado. Nesse 
sentido, indicamos a possibilidade de dividir a história do curso em outras duas, quando da inauguração do mestrado, nos anos 1970, e do doutorado, nos anos 1990, sendo esta uma indicação para futuros trabalhos.

Salientamos a importância de se desenvolverem estudos sobre outras faculdades, a fim de identificar tanto as peculiaridades como as interseções entre elas. Além disso, seria relevante identificar outros atores significativos que contribuíram para o estabelecimento da Administração no Brasil e seus interrelacionamentos, para que se possa compreender mais especificamente a interação entre os saberes importados de outros países, especialmente dos EUA, e o cenário brasileiro no qual se inseriram, realidade bastante diferente daquela onde foram originalmente desenvolvidos. Também é pertinente a discussão sobre outros atores que foram responsáveis por reproduzir e reforçar a pertinência no país de conhecimentos produzidos fora, como consultorias, gurus, periódicos, programas de especialização e, mesmo, o empresariado (que pode contribuir para importar e disseminar discursos adequados aos seus interesses; ver, por exemplo, Zanetti e Vargas, 2007).

Acreditamos que os apelos à cientificidade e universalidade foram importantes para legitimar a importação de conhecimentos, bem como a supremacia econômica estadunidense e o poder político desempenhado pelos atores interessados, materializado no delineamento dos contornos da disciplina e na disseminação de suas práticas. Discutir a história do desenvolvimento dos saberes administrativos do Brasil é importante para que o cenário atual possa ser mais bem compreendido, habilitando, assim, a necessária reflexão acerca da adequação dos conhecimentos à realidade brasileira.

Entender a história da FACE e seu pioneirismo no estabelecimento dos cursos superiores em Administração - apesar de sua posição subordinada no campo, especialmente a partir do final da década de 1950 - é, então, uma forma de trazer mais elementos para compreender o campo da Administração no Brasil e como ele se estabeleceu, inclusive nas suas relações com a sociedade que o abriga. A retomada da história dos cursos de Administração da FACE permitiu também compreender melhor as vicissitudes do desenvolvimento desses bacharelados que tiveram e atualmente ainda têm papel relevante na disseminação do management.

\section{Referências}

ALCADIPANI, R.; BERTERO, C. O. Guerra Fria e ensino do management no Brasil: o caso da FGV-EAESP. Revista de Administração de Empresas, v. 52, n. 3, p. 284-299, Maio-Jun. 2012a.

Uma escola norte-americana no Ultramar? Uma historiografia da Escola de Administração de Empresas de São Paulo na Fundação Getulio Vargas. In: ENCONTRO DA ASSOCIAÇÃO NACIONAL DE PÓSGRADUAÇÃO E PESQUISA EM ADMINISTRAÇÃO, 2012, Rio de Janeiro. Anais... 2012b.

BAHIA, C.L.M. Belo Horizonte: uma cidade para a modernidade mineira. Cadernos de Arquitetura e Urbanismo, v. 12, n. 13, p. 185-200, dez. 2005.

BARROS, A; CARRIERI, A. Ensino superior em Administração entre os anos 1940 e 1950: uma discussão a partir dos acordos de cooperação Brasil-Estados Unidos. Cad. EBAPE.BR, v. 11, n. 2, p. 256-273, Jun. 2013.

BELL, P. 'Para os EUA Brasil era campo de batalha na Guerra-Fria'. Entrevista concedida a Felipe Werneck; Heloísa Sturm. Estado de São Paulo, 16 de setembro de 2012. Disponível em: <http://www.estadao.com.br/noticias/impresso,para-os-eua-brasil-era-campo-de-batalha-na-guerra-fria-,931221,0.htm>. Acesso em: 01 mar. 2013.

BOOTH, C.; ROWLINSON, M. Management and organizational history: prospects. Management and Organizational History, v. 1, n. 1, p. 5-30, Feb. 2006.

BRASIL. Decreto-Lei n. $\mathbf{7 . 9 8 8} \quad-\quad$ de 22 setembro de 1945 . Disponível em: <http://www6.senado.gov.br/legislacao/ListaPublicacoes.action?id=27880>. Acesso em: 15 jan. 2011. 
Comissão Consultiva de Administração Pública. Programa da Comissão Consultiva de Administração Pública no Brasil. Rio de Janeiro. $1^{\circ}$ de março de 1953. 35 f.

CARTER, C.; MCKINLAY, A.; ROWLISON, M. Introduction: Foucault, management and history. Organization, v. 9, n. 4, p. 515-526, Nov. 2002.

CARvalho, J. A. M. Projeto Memória Oral da Ciência na Universidade Federal de Minas Gerais. Entrevista concedida a Otávio Soares Dulci. fev., 2007. p. 1-46. (mimeo).

CASTRO, C. de M. 1974-1989: a institucionalização da pós-graduação no Brasil. In: FERREIRA, M. M.; MOREIRA, R. L. (Orgs.). CAPES 50 anos: depoimentos ao CPDOC/FGV. Rio de Janeiro: Fundação Getulio Vargas; Brasília, DF: CAPES, 2002. p. 84-103.

CLARK, P.; ROWLISON, M. The treatment of History in Organization Studies: towards an 'historic turn'? Business History, v. 46, n. 3, p. 331-352, July, 2004

COELHO, F. de S. Educação superior, formação de administradores e setor público: um estudo sobre o ensino de administração pública - em nível de graduação - no Brasil. 2006. 151 f. Tese (Doutorado em Administração) - Escola de Administração de Empresas de São Paulo. São Paulo, 2006.

COHN, G. Entrevista realizada em maio de 2004. In: BASTOS, E.R. et al. Conversa com Sociólogos Brasileiros. São Paulo: Editora 34, 2006. p. 115-134.

CUNHA, R. de A. A universidade ao tempo de seu jubileu de prata. Revista da Universidade de Minas Gerais, n. 10, p. 7-11, maio, 1953 .

CUNNINGHAM, J.L. Preface. In: MAUCK, E. A. The establishment of a public administration training program in the School of Economic Sciences U.M.G. under a project agreement between The Institute of Inter-American Affairs and the University of Minas Gerais, Brazil. Belo Horizonte: Institute of Inter-American Affairs, 1954.

CURADO, I. B. O desenvolvimento dos saberes administrativos em São Paulo. 2001. Tese (Doutorado em Administração) - Fundação Getulio Vargas, São Paulo, 2001a.

Pesquisa historiográfica em Administração: uma proposta metodológica. In: ENCONTRO ANUAL DA ANPAD, XXV. Campinas, 2001. Anais... São Paulo: ANPAD, 2001b.

DEPARTAMENTO DE CIÊNCIAS ADMINISTRATIVAS. Histórico do Curso de Administração. v.1, 1952 a 1984. Belo Horizonte: Departamento de Ciências Administrativas da UFMG.

DULCI, O. Empresariado e política em Minas Gerais". Revista do Departamento de História, UFMG, n. 10 e Cadernos do DCP, UFMG, n.8, p. 93-124,1990. (edição conjunta)

FACULDADE DE CIÊNCIAS ECONOMICAS (FACE). Parecer sobre a permanência do curso de Administração Pública (Mimeo), 1968, s.p. Disponível no caderno de atas da congregação da FACE.

FISCHER, T. O ensino de administração pública no Brasil: da tutela estrangeira à autonomia necessária. In: REUNIÃO NACIONAL DA ANPAD, Belo Horizonte, 1985. Anais... Florianópolis-SC: 1985. Ed. da UFSC, 1985.p. 165-170.

FOUCAULT, M. A arqueologia do saber. Rio de Janeiro: Forense Universitária, 2008.

GRAMSCI, A. Cadernos do Cárcere.Rio de Janeiro: Civilização Brasileira. v. 1. 4. ed.2006.

JACQUES, R. Manufacturing the employee. London: Sage Publications, 1996.

KEINERT, F.C.; SILVA, D.P. A gênese da ciência política brasileira. Tempo Social, Revista de Sociologia da USP, v. 22, n. 1, p. 79-98, jun. 2010.

LOCKE, R. The collapse of the American management mystique. Oxford: Oxford University Press, 1996. 
MACHADO, M.B. O Ensino de Administração Pública no Brasil. Rio de Janeiro: Editora da Fundação Getúlio Vargas, 1966.

MARTINS, C. B. Surgimento e expansão dos cursos de administração no Brasil. Ciência e Cultura (Revista da Sociedade Brasileira para o Progresso da Ciência), v. 41, n. 7, p. 663-676, jul. 1989.

MAUCK, E.A. The Establishment of a Public Administration Training Program in the School of Economic Sciences U.M.G. under a project agreement between The Institute of Inter-American Affairs and the University of Minas Gerais, Brazil. Belo Horizonte: Institute of Inter-American Affairs, 1954a. jul./dez.1954b.

El estudio de la administración publica. Revista da Faculdade de Ciências Econômicas, v. 3, n. 6, p. 68-83,

MiClethWAit, J.; WOOLDRIGE, A. A future perfect: the challenge and promise of globalization. New York: Random House, 2003.

MINISTÉRIO DA EDUCAÇÃO E DA CULTURA. Comissão de Estatutos Regulamentos e Regimentos. Parecer $\mathbf{n}^{\circ}$ 552. 23 de novembro de 1960 .

MOTTA, F.C.P. A questão da formação do administrador. Revista de Administração de Empresas, Rio de Janeiro, v. 4, n. 23, p. 53-55, out./dez. 1983.

NICOLINI, A. M. Qual será o futuro das fábricas de administradores? Revista de Administração de Empresas, São Paulo, v. 43, n. 2, p. 44-54, 2003.

PARKER, M. Against Management. Oxford: Polity, 2002.

PAULA, J. A. Passado e Presente de uma Instituição: memória da Faculdade de Ciências Econômicas/UFMG. Belo Horizonte: UFMG/FACE/CEDEPLAR, 1991.

PINTO, Y. L. de M. O movimento "estudantil" de 1960 na Faculdade de Ciências Econômicas da Universidade de Minas Gerais: esclarecimentos prestados pelo antigo diretor da Faculdade. Belo Horizonte: Santa Maria, 1963.

REED, M. Rediscovering Hegel: the 'new historicism' in organization and management studies. Journal of Management Studies, v. 33, n. 2, p. 139-158, 1996.

REIS, E. Situando a Sociologia Política. Entrevista para a revista Política \& Sociedade. Política e Sociedade, v. 1, n. 1, p. 11-35, set. 2002 .

RODRIGUES, M. A.; LUZ, T. R. Curso de Graduação em Administração. Belo Horizonte: Departamento de Ciências Administrativas da UFMG, 35f.

ROWLINSON, M; JACQUES, R; BOOTH, C. Critical management and organizational history. In: ALVESSON, M; BRIDGMAN, T; WILLMOTT, H. (Eds.). The Oxford handbook of critical management studies. Oxford: Oxford University Press, 2009. p. 286-304.

SIEGEL, G. The school of public administration involvement in international education and institution building programs. In: CLAYTON, R. et al. Futures of the Past: collected papers in celebration of its more than eighty years University of Southern California's School of Policy, Planning and Development. Bloomington: Iuniverse, 2010. p. $371-400$

SPIANDORElo, S. C. Fragmentos da Constituição da Profissão de Administrador (1931-1966). Dissertação (Mestrado em Administração). Universidade São Francisco, 2008.

TAYLOR, D. A. Institution building in business administration: the Brazilian experience. East Lansing: Michigan State University, 1968. 
ÜSDIKEM, B.; KIESER, A. Introduction: history in organization studies. Business History, v. 46, n. 3, p. 321-330, July, 2004.

VALE, M. P. Institucionalização do ensino em Administração de empresas na cidade de São Paulo: um estudo de caso na Faculdade de Economia, Administração e Contabilidade da Universidade de São Paulo (FEA-USP). Dissertação (Mestrado em Administração). FEA-USP. São Paulo, 2012.

VIZEU, F. Management no Brasil em perspectiva histórica: o projeto do IDORT nas décadas de 1930 e 1940 . Tese (Doutorado em Administração). EAESP/FGV. São Paulo: 2008.

WEATHERBEE, T. G. Caution! This historiography makes wide turns: historic turns and breaks in management and organization studies. Management \& Organizational History, v. 7, n.3, p. 203-218, Aug. 2012.

WHITEHOUSE. Report to Congress on the Mutual Security Program.1953. Disponível em: <http://www30.us.archive.org/stream/reporttocongress1953unit/reporttocongress1953unit_djvu.txt>. Acesso em 27 nov. 2012.

WOOD JR., T; TONELLI, M. J; COOKE, B. Colonização e neocolonização da gestão de recursos humanos no Brasil (1950-2010). Rev. Adm. Empresas [online], v. 51, n. 3, p. 232-243, 2011.

ZANETTI, A.; VARGAS, J. T. Taylorismo e fordismo na indústria paulista: o empresariado e os projetos de organização racional do trabalho, 1920 - 1940. São Paulo: Associação Editorial Humanista, 2007. 